\title{
Somatic Embryogenesis from Leaf and Shoot tip Explants of Jatropha curcas L.
}

\author{
Srikanth Reddy Medipally ${ }^{1,2}$, B. Naresh ${ }^{1,3^{*}}$, S. Manoj Kumar ${ }^{1}$, \\ Fatimah Md. Yusoff ${ }^{2}$ and Prathibha Devi ${ }^{1}$ \\ 'Biotechnology Laboratory, Department of Botany, Osmania University, Hyderabad-500007, Telangana, India \\ ${ }^{2}$ Laboratory of Marine Biotechnology, Institute of Bioscience, Universiti Putra Malaysia, \\ 43400 UPM Serdang, Selangor Darul Ehsan, Malaysia \\ ${ }^{3}$ Department of Botany, Narendra PG College, Telangana University, Armoor, \\ Nizamabad-503224, Telangana, India; beerelli.naresh@gmail.com
}

\begin{abstract}
Jatropha curcas is a non-edible oil plant species and belongs to Euphorbiaceae family. It is gaining the importance as potential renewable feed-stock for biodiesel production. Here in the present study we developed an efficient micropropagation protocol through somatic embryogenesis from leaf and shoot tip explants of Jatropha curcas. Murashigae-Skoog medium supplemented with 2 , 4-D $(0.5 \mathrm{mg} / \mathrm{l})$ and benzylaminopurine $(5 \mathrm{mg} / \mathrm{l})$ resulted in the production of green embryogenic callus with clearly differentiated somatic embryos with a frequency of plant conversion rate from shoot tip and leaf explants was $51 \pm 0.9$ and $54 \pm 0.6$ respectively. The regenerated shoots were rooted on root induction medium, transplanted to pots and later transferred to field. The survival percentage of the transplanted plants was $33 \pm 0.1$ for shoot tip and $24 \pm 0.7$ for leaf explant. Therefore, this protocol could be useful for micropropagation of Jatropha curcas as effective feed-stock towards biodiesel production.
\end{abstract}

Keywords: Physic Nut, Micropropagation, MS Medium, Biodiesel, Euphorbiaceae

\section{Introduction}

Global warming, increases in crude oil prices, limited resources of fossil fuel have driven the importance for renewable energy sources such as biofuels (eg. biodiesel, bioethanol, biogas etc.). Biodiesel is an alternative diesel fuel made from different types of renewable sources such as vegetable oils and animal fats. It is environmentally friendly fuel with low emission profiles and also non-toxic and biodegradable ${ }^{1,2}$. Biofuels derived from non-edible oils such as Physic nut (Jatropha curcas), mahua (Madhuka indica J.F. Gmel), cardoon (Cynara cardunculus L.), Paradise tree (Simarouba glauca), castor (Ricinus communis L.), Karanj (Pongamia pinnata) are more economical and suitable compared to edible oils ${ }^{3-}$ ${ }^{5}$. In some of the developed nations (US and European countries) edible oils such as rape seed and soybean oils are used for biodiesel conversion. However, in developing countries usage of edible oils for biofuels is not feasible ${ }^{6}$. Among non-edible oil crops Jatropha curcas is identified as the most potential renewable feed-stock for biodiesel production $^{7,8}$.

Jatropha curcas is a small tree or large shrub belonging to the family Euphorbiaceae, it is also called as purging nut or physic nut. It is a drought-resistant species which is extensively cultivated in the tropical areas as a living fence. Jatropha also has many advantages such as it is more suitable for tropical and subtropical conditions, higher seed productivity and rapid growth ${ }^{9,10}$. Other than the biofuel production, Jatropha tree also has lot of applications, every part of the tree such as roots, leaves, latex, fruits and seed oil has medicinal properties. The seed-oil has lot

${ }^{*}$ Author for correspondence 
of insecticidal, molluscicidal and fungicidal properties ${ }^{11}$, 12. Owing to these tremendous applications, at present there is a great need for the development of good disease resistant and fast yielding varieties in Jatropha especially as biodiesel from seed-oil. Plant tissue culture technology is the most suitable way to propagate efficiently Jatropha curcas varieties for biodiesel feed-stock.

In vitro propagation of $J$. curcas is initially difficult due to the presence of latex in the plant; however this can be minimized by pretreatment of the explant with $10 \%$ Hydrogen peroxide ${ }^{13-18}$. The present study was carried out to standardize efficient protocols for micropropagation Karimnagar genotype of Jatropha curcas via direct somatic embryogenesis of leaf and shoot tip explants.

\section{Materials and Methods}

\subsection{Plant Material}

Seeds of the Jatropha curcas were collected from wild plants located at Venkatapur village, Sircilla Mandal, Karimnagar district, Andhra Pradesh, India. In addition to their use in in vitro studies, the seeds were also planted in the Botanical Garden of Department of Botany, Osmania University, Hyderabad and a plantation was raised in the form of a green hedge.

\subsection{Somatic Embryogenesis}

The explants comprised of leaf and shoot tips which were collected from nine months old plants growing in Botanical Garden, Osmania University. Explants were initially rinsed in $10 \%$ hydrogen peroxide for 3 minutes and transferred to $50 \%$ ethanol for 2 minutes, washed in sterile distilled water and immersed in $0.1 \%(\mathrm{w} / \mathrm{v})$ mercuric chloride containing two drops of Tween-20 for 5 minutes with intermittent shaking. The explants were then washed thrice with sterile distilled water and inoculated into sterile 25 X $150 \mathrm{~mm}$ culture tubes containing MS medium supplemented with $3 \%(\mathrm{w} / \mathrm{v})$ sucrose, $0.8 \%(\mathrm{w} / \mathrm{v})$ phytaagar (Himedia Laboratories, India) and the appropriate combinations of growth regulators. The $\mathrm{pH}$ was adjusted to 5.8 before autoclaving using $0.1 \mathrm{~N} \mathrm{NaOH}$ and $0.1 \mathrm{~N}$ $\mathrm{HCl}$. One hundred and fifty explants were inoculated for each experiment with three replicates amounting to a total of 450 explants. All the cultures were sub-cultured for every 10-12 days. The cultures were maintained in a sterile growth room with 16 hours photoperiod at $25 \pm 2_{-2}^{\circ} \mathrm{C}$ with light intensity of $60 \mu \mathrm{Em} \mathrm{s}^{-2}$ and $50 \%$ relative humidity.
MS media supplemented with 2, 4-D (0.5 mg/l), BA (0.5 mg/l), Glutamine $(684.2 \mu \mathrm{M})$ and Citric acid (520.5 $\mu \mathrm{M})$ [Medium-A] was used as the medium for somatic embryogenesis. The explants with somatic embryos were transferred to plant conversion medium [MS medium supplemented with BA (2 mg/l), Glu $(684.2 \mu \mathrm{M})$ and CA $(520.5 \mu \mathrm{M})]$ (Medium-B) for conversion of somatic embryos to plantlets. Healthy, well developed and elongated shoots $(3 \mathrm{~cm})$ were transferred to root induction medium [Half strength MS supplemented with IBA (2 $\mathrm{mg} / \mathrm{l})$, Glu $(684.2 \mu \mathrm{M})$ and CA $(520.5 \mu \mathrm{M})]$ (Medium-C). Healthy, plantlets with well-developed roots were transferred to pots and gradually acclimatized in the glasshouse in the shade for two weeks by enclosing the pots in polythene bags. Subsequently, the plants were transferred to the sunny areas of the glasshouse and later to the field.

\subsection{Histological Studies}

Histological studies were performed to observe the formation of different stages in somatic embryogenesis process $^{19}$. Explants were fixed in 3:1 ratio of alcohol and glacial acetic acid. A series of dehydration steps were made in 30-70\% of tertiary butyl alcohol and xylene was used as clearing agent to make the tissue translucent. The tissue was then impregnated in paraffin $\left(56-58^{\circ} \mathrm{C}\right)$ and placed in the embedded unit (Electron Corporation, model Shandon Histocenter-3). The material was processed by Citadel-2000 Thermo Shandon. The processed material was stained with Haemotoxylin and Eosin using an automated Leica Auto stainer-Xl. The stained blocks were mounted and trimmed with Leica model RM 2155 microtome to make very thin microsections of about 6-8 $\mu \mathrm{m}$. The microsections were mounted, dewaxed and observed under microscope (Leitz Diaplan). Microphotographs of different stages of somatic embryogenesis were acquired using digital camera.

\subsection{Statistical Analysis}

Each experiment was repeated twice with three replicates/treatments and the data was presented as mean \pm standard error of the three replicates.

\section{Results and Discussion}

In the present work, micropropagation through somatic embryogenesis was standardized from leaf and shoot tip explants of the Karimnagar genotype of Jatropha curcas. 
This is the second highest oil producing genotype in India and also its oil has good biochemical characteristics suitable for biodiesel conversion ${ }^{4}$. Therefore, this accession was selected for further micropropagation studies for production of efficient feed-stock for biodiesel production. Previous studies presented the micropropagation protocols from different accessions of Jatropha curcas ${ }^{17,18}$. Till to date very limited research was carried out on the micropropagation of Jatropha curcas through somatic embryogenesis ${ }^{20}$. In this study an attempt was made to develop efficient protocols for plant regeneration through somatic embryogenesis from shoot tip and leaf explant.

MS medium was supplemented with BA $(0.5 \% \mathrm{mg} / \mathrm{l})$ and 2, 4-D $(0.5 \mathrm{mg} / \mathrm{l})$ resulted in good response of shoot tip and leaf explants in the development of green embryogenic callus with clearly differentiated somatic embryos (Figure $1 \mathrm{~b}$ and $\mathrm{d}$ ). The response was genotype independent. The percentage production of somatic embryogenic callus from leaf explant was $66 \pm 0.4$; shoot tip produced green compact callus with low percentage value of $36 \pm 0.6$
(Table 1). The embryogenic callus was carefully cultured and by the $4^{\text {th }}$ week, somatic embryos were differentiated from it and which developed gradually into plantlets by passing through various developmental stages like globular, heart and torpedo shaped embryos.

The developmental process pertaining to embryogenesis (somatic embryos) was studied by histological methods. The different stages of somatic embryos viz: globular, heart and torpedo shaped stages were observed (Figure 1e). The Figure 1 demonstrates the fact that response of plant regeneration explained above in terms of somatic embryogenesis occurred normally in accordance with the pattern of development of zygotic embryo of angiosperms. Hence, the results and discussion regarding organogenesis and embryogenesis presented above stand validated in accordance with Devi et al., Syamala and Devi and Kumar et al., ${ }^{21-23}$.

Somatic embryos have the potential to develop into plantlets. Hence, these somatic embryos were further sub-cultured on a different culture medium to induce their germination and conversion into plantlets. The

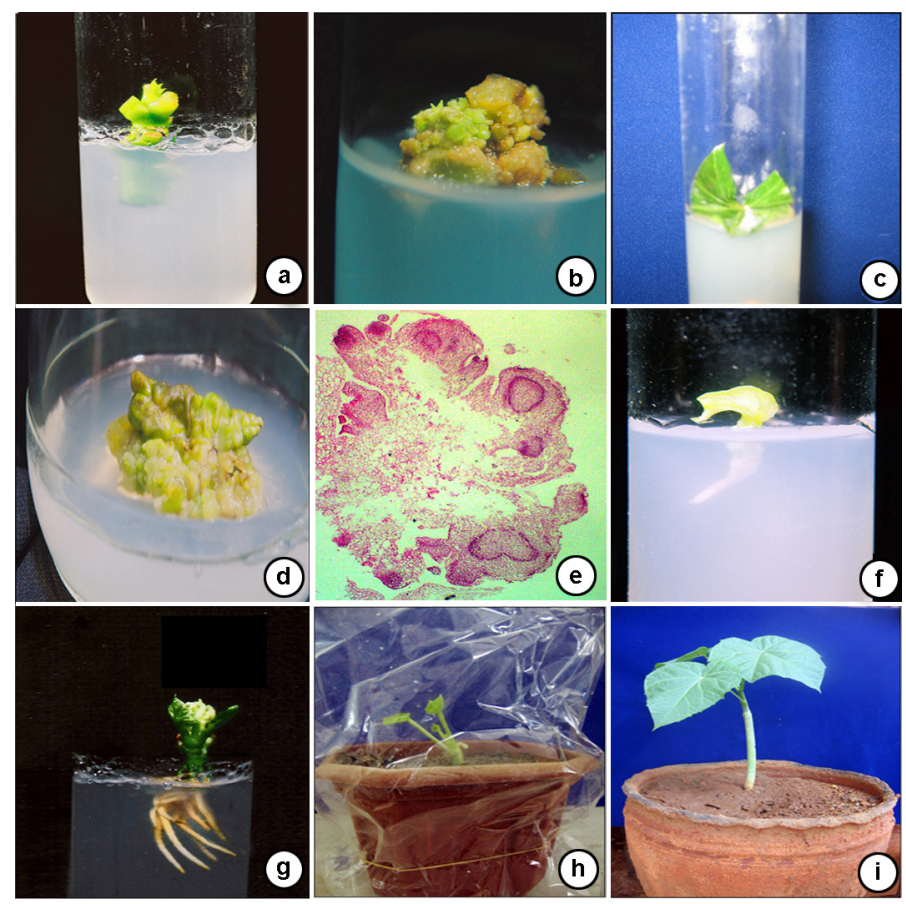

Figure 1. Somatic embryogenesis and plant regeneration from leaf and shoot tip explants of Jatropha curcas. (a) Shoot tip explant on medium-A. (b) Proembryos from the embryogenic callus produced from the shoot tip explants. (c) Leaf explant on medium-A. (d) Proembryos from the embryogenic callus that was developed from leaf explants. (e) Histological section showing heart shaped and oval shaped somatic embryos. (f) Plantlets of Jatropha curcas converted from somatic embryos on medium-B. (g) Well developed roots from the plantlets inoculated on root induction medium-C. (h) A plantlet transferred to pot and gradually acclimatized in the glasshouse before transfer to the Botanical garden. (i) Well established plantlet in the glasshouse before it transferred to the Botanical garden. 


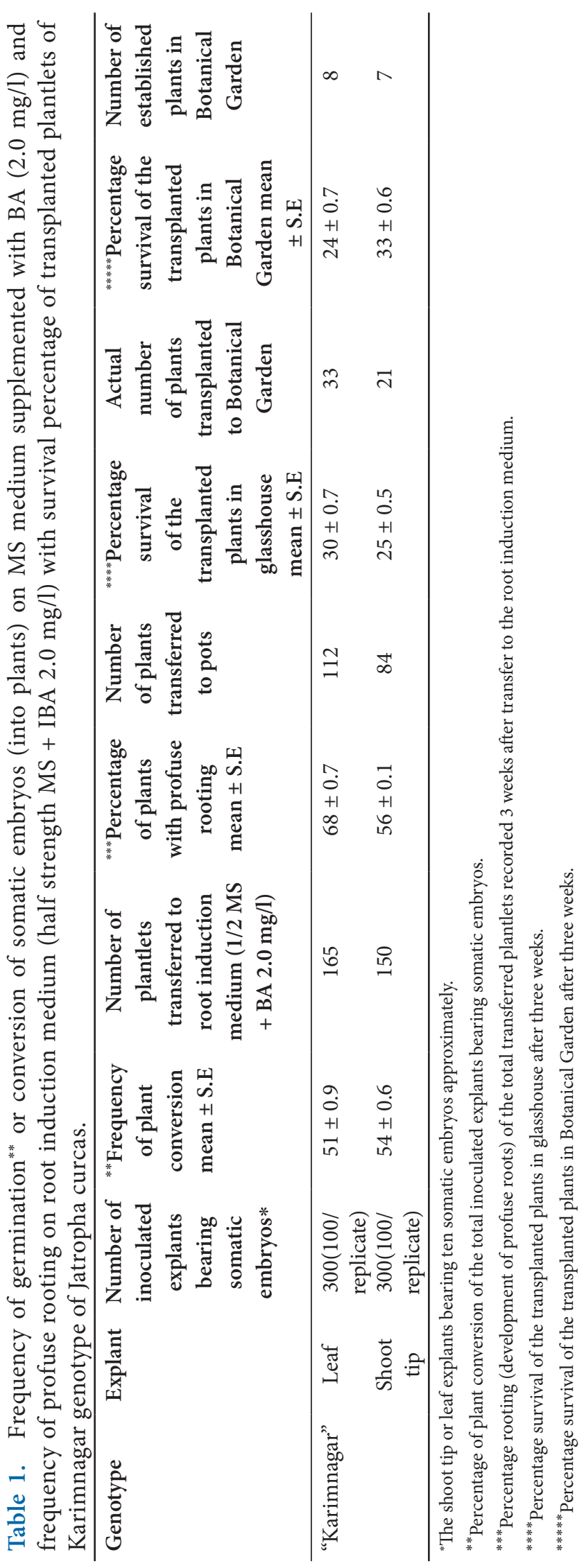

somatic embryos were cultured on MS medium supplemented with $2.0 \mathrm{mg} / \mathrm{l} \mathrm{BA}$ responded well by efficient shoot development with good frequencies (Table 1). The shoots regenerated from different explants were rooted efficiently on half strength MS medium supplemented with different concentrations of IBA $(1.0,2.0$ and $3.0 \mathrm{mg} / \mathrm{l})$. The highest frequency of rooting $(60 \%)$ was recorded on the culture medium containing $2.0 \mathrm{mg} / \mathrm{l}$ IBA. Sujatha and Prabhakaran ${ }^{24}$, and Rajore and Batra ${ }^{15}$ reported good rooting with various concentration of IBA similar to the present observation. Root induction was reported by addition of NAA to the half strength basal medium ${ }^{13}$ and also on MS medium without growth regulators ${ }^{13,14}$.

A total of $25 \%$ and $30 \%$ of the plantlets developed from shoot tip and leaf explants were transplanted to pots and acclimatized in the glass house for two weeks. The actual number of plants transplanted to Botanical Garden was 21 and 33 of shoot tip and leaf explants and the percentage survival was 33 and 24 (Table 1). Fifteen plants of "Karimnagar" Jatropha curcas genotype are now growing in the Botanical Garden.

\section{Conclusion}

Jatropha curcas is the current potential renewable energy feed-stock for biodiesel production. From the present study a standardized protocol for efficient plantlet regeneration was developed. Somatic embryogenesis from the shoot tip and leaf explant of Jatropha curcas is a suitable method for micropropagation. This protocol of plant regeneration could be applied for high quality biomass production from this species.

\section{References}

1. Krawczyk, T. Biodiesel - Alternative fuel makes inroads but hurdles remain. INFORM, 1996; 7, 801-829.

2. Abdulla, R., Chan, E. S., \& Ravindra, P. Biodiesel production from Jatropha curcas: a critical review. Critical Reviews in Biotechnology, 2011; 31, 53-64.

3. Sengo, I., Gominho, J., Orey, L., Martins, M., AlmeidaDuarte, E., Pereira, H., \& Ferreira-Dias, S. Response surface modeling and optimization of biodieselproduction from Cynara cardunculus oil. European Journal of Lipid Science and Technology, 2010; 112, 310-320.

4. Naresh, B., Reddy, M. S., Vijayalakshmi, P., Reddy, V., \& Devi, P. Physico-chemical screening of accessions of 
Jatropha curcas for biodiesel production. Biomass \& Bioenergy, 2012; 40, 155-161.

5. Bankovi'c-Ili'c, I. B., Stamenkovi'c, S. O., \& Veljkovi'c, V. B. Biodiesel production from non-edible plant oils. Renewable \& Sustainable Energy Reviews, 2012; 16, 36213647.

6. Knothe G. Monitoring a progressing transesterification reaction by fiber-optic near infrared spectroscopy with correlation to $1 \mathrm{H}$ nuclear magnetic resonance spectroscopy. Journal of American Oil Chemists Society, 2000; 77, 489493.

7. Koh, M. Y., \& Ghazi, T. I. M. A review of biodiesel production from Jatropha curcas L. oil. Renewable \& Sustainable Energy Reviews, 2011; 15, 2240-2251.

8. Choudhury, H. A., Goswami, P. P., Malani, R. S., \& Moholkar, V. S. Ultrasonic biodiesel synthesis from crude Jatropha curcas oil with heterogeneous base catalyst: Mechanistic insight and statistical optimization. Ultrasonics Sonochemistry, 2014; 21, 1050-1064.

9. Fairless, D. Biofuel: the little shrub that could - maybe. Nature, 2007; 449, 652-655.

10. Madhaiyan, M., Peng, N., Te, N. S., Hsin C. I., Lin, C., Lin, F., Reddy, C., Yan, H., \& Ji, L. Improvement of plant growth and seed yield in Jatropha curcas by a novel nitrogen-fixing root associated Enterobacter species. Biotechnology for Biofuels, 2013; 6, 140.

11. Ginwal, H. S., Phartyal, S. S., Rawat, P.S., \& Srivastava, R. L. Seed source variation in morphology, germination and seedling growth of Jatropha crucas Linn. in Central India. Silvae Genetica, 2005; 54, 76-80.

12. Devi, P. (2012). Status of Bioenergy Research and Jatropha in India: A Review. In N. Carels, M. Sujatha, \& B. Bahadur (Eds.) Jatropha, Challenges for a New Energy Crop (pp. 31-51). New York: Vol. I, Springer Science+Business Media.

13. Sujatha, M., \& Mukta, N. Morphogenesis and plant regeneration from tissue cultures of Jatropha curcas. Plant Cell Tissue and Organ Culture, 1996; 44, 135-141.

14. Wei, Q., Lu, W., Da, L. Y., Pan, S. L., Xu, Y., Tang, L., \& Chen, F. Plant regeneration from epicotyl explant of Jatropha cur- cas. Journal of Plant Physiology Molecular Biology, 2004; 30, 475-478.

15. Rajore, S., \& Batra, Amla. Efficient Plant Regeneration via Shoot Tip Explant in Jatropha curcas (L.) Journal of Plant Biochemistry and Biotechnology, 2005; 14, 73-75.

16. Sujatha, M., Makkar, H. P. S., \& Becker, K. Shoot bud proliferation from axillary nodes and leaf sections of non-toxic Jatropha curcas L. Plant Growth Regulation, 2005; 47, 83-90.

17. Leela, T., Naresh, B., Reddy, M. S., Madhusudhan, N. Ch., \& Cherku, P. D. Morphological, physico-chemical and micropropagation studies in Jatropha curcas L. and RAPD analysis of the regenerants. Applied Energy, 2011; 88, 20712079.

18. Naresh, B., Dhanasri, G., Reddy, M. S., \& Cherku, P. D. Development of Efficient Micropropagation Protocols of Elite Accessions of Jatropha curcas L. Plant Tissue Culture \& Biotechnology, 2013; 23, 231-239.

19. Luna GL. Manual of histological staining methods of the AFLP. III ed. McGraw Hill; 1998.

20. Jyothi, S., Amla, B., \& Deewan, J. A. An expeditious method for regeneration of somatic embryos in Jatropha curcas $\mathrm{L}$. Phytomorphology, 2000; 50, 239-242.

21. Devi, P., Zhong H., \& Sticklen, M. B.. In vitro morphogenesis of pearl millet [Pennisetum glaucum (L.) R.Br.] Efficient production of multiple shoots and inflorescence from shoot apices. Plant Cell Reports, 2000; 19, 546-550.

22. Syamala, D., \& Devi, P. Development of plant regeneration and Genetic transformation system form shoot apics of Sorghum bicolor (L.) Moench. Journal of Plant Biotechnology, 2000; 2, 77-85.

23. Kumar, S. M., Syamala, D., Sharma, K.K., \& Devi, P. Protocol for efficient plant regeneration and Agrobacterium tumifaciens mediated genetic transformation of Pigeonpea (Cajanus cajan (L) millsp.). Indian Journal of Genetics, 2003; 63, 289- 294.

24. Sujatha, M., \& Prabakaran, A. J. (2003). New ornamental Jatropha hybrids through interspecific hybridization. Genetic Resources and Crop Evolution, 2003; 50, 75-82. 